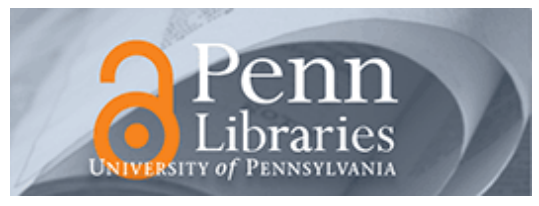

University of Pennsylvania

ScholarlyCommons

Marketing Papers

Wharton Faculty Research

2008

\title{
An Empirical Investigation of the Impact of Communication Timing on Customer Equity
}

Xavier Drèze

University of Pennsylvania

André Bonfrer

Follow this and additional works at: https://repository.upenn.edu/marketing_papers

Part of the Business and Corporate Communications Commons, E-Commerce Commons, and the Marketing Commons

Recommended Citation

Drèze, X., \& Bonfrer, A. (2008). An Empirical Investigation of the Impact of Communication Timing on Customer Equity. Journal of Interactive Marketing, 22 (1), 36-50. http://dx.doi.org/10.1002/dir.20105

This paper is posted at ScholarlyCommons. https://repository.upenn.edu/marketing_papers/184

For more information, please contact repository@pobox.upenn.edu. 


\title{
An Empirical Investigation of the Impact of Communication Timing on Customer Equity
}

\author{
Abstract \\ This research examines the impact of communication frequency on customer retention and spending and \\ thus,ultimately,on a firm's Customer Equity (CE). We conduct an empirical study in the context of \\ permission-based e-mail marketing in the entertainment industry and find that intercommunication timing \\ has a dramatic impact on customer behavior. Message scheduling affects both attrition and the customer \\ response and thus has a critical impact on the value of one's customer base. The impact of intercontact \\ duration is asymmetric in that too long intercommunication time is less problematic than too short \\ intercommunication time.

\section{Disciplines} \\ Business | Business and Corporate Communications | E-Commerce | Marketing
}




\section{An Empirical Investigation of the Impact of \\ Communication Timing on Customer Equity}

August 25, 2005

Xavier Drèze

André Bonfrer ${ }^{*}$

* Xavier Drèze is Assistant Professor of Marketing at the Wharton School of the University of Pennsylvania, 3730 Walnut Street, Philadelphia, PA 19104-6340, 215898-1223, Fax 215-898-2534, xdreze@wharton.upenn.edu. André Bonfrer is Assistant Professor of Marketing at the Singapore Management University. This research was funded in part by the Wharton-SMU research center, Singapore Management University and in part by a WeBI - Mac Center Grant. 


\title{
An Empirical Investigation of the Impact of \\ Communication Timing on Customer Equity
}

\begin{abstract}
The marketing literature has acknowledged the importance of Customer Equity (CE) as a benchmark for marketing performance. In this paper, we are interested in understanding the impact of communication frequency on customer retention and spending and thus, ultimately, on a firm's $C E$. An empirical study of this impact is conducted in the context of permission-based email marketing in the entertainment industry.

We find that inter-communication time has a dramatic impact on customer behavior. It affects both attrition and consumer surplus and thus has a critical impact on the value of a customer database. This impact is asymmetric; managers are advised to err on the side of longer rather than shorter inter-communication times.
\end{abstract}

Keywords: Customer relationship management, database marketing, customer equity, customer retention. 


\section{Introduction}

An underlying theme of most direct marketing research is that firms are trying to maximize their Customer Equity (Blattberg and Deighton 1996, Berger et al 2002, Rust, Lemon, and Zeithaml 2004) or the net present value of their current and future customers. While much of the recent research provides marketers with powerful analytical tools for selecting customers to receive a (direct) marketing communication (e.g., Bult and Wansbeek 1995, Gönül and Shi 1998, Gönül and Ter Hofstede 2003), there has been little attempt made to treat the timing of such marketing activities endogenously when calculating or maximizing the value of customer names. Consequently, the primary research objective of this paper is to examine the importance of the frequency of contact between a marketer and a customer, and show how a sub-optimal communication frequency (too much or too little contact) impacts the value of a customer database.

When attempting to maximize the customer lifetime value, the extant research has taken the frequency of contact as a given. This is a natural thing to do when one is concerned with catalogs or newsletters as these vehicles have a natural periodicity that marketers adhere to. For instance, fashion catalogs are sent based on seasons (Winter, Spring, Summer, and Fall); newsletters are sent on a monthly or weekly basis.

However, given the recent move towards personalization and customization, we believe that contact frequency must be made endogenous when trying to maximize the value of a customer's name. Hence, we propose an empirical investigation of the impact of contact frequency on customer equity. When doing so, we look at the impact of contact frequency on retention and on customer behavior. This is a crucial analysis as trying to maximize short term 
revenues might lead a firm to contact customers with such a high frequency that they decide to sever their relationship with the company. This would in effect drive the lifetime value to zero a counter-productive effort! Similarly, as one starts manipulating the frequency of contacts, one will affect customer responses to the communications. Indeed, consider the Book of the Month Club. One would not expect a Book of the Year, or the Book of the Day club to be as appealing.

When we make contact frequency endogenous in a customer equity $(C E)$ model, we find that it has a critical impact on the value of the names held in a company's database. We find that excessive marketing communications lead to higher customer defection and thereby reduce customer equity. In contrast, if a firm does not communicate with customers frequently enough, the firm loses out on opportunities to make sufficient money on these customer names. This latter effect is amplified by the fact that future earnings are less valuable than current ones.

\section{Background and Motivation}

There are two important components to the lifetime valuation of a customer: the duration of the relationship and the value of each customer-firm interaction. In terms of the first component, duration, it has long been thought that firms benefit more from maintaining long-term than from short-term customer relationships (e.g., see Bendapudi and Berry, 1997). There appears to be considerable anecdotal evidence on the value of these long-term customer relationships (it is often said that it is cheaper to keep a customer than to get a new one), but academic research has generated very few generalizable empirical results that can substantiate this hypothesized rising profitability of long term customers (except for Reichfeld and Teal, 1996). In a recent and wellcited Sloan Management Review article, Dowling and Uncles (1997) challenge customer loyalty programs, and caution that long life (or loyal) customers are not necessarily more profitable. 
Reinartz and Kumar (2000) provide empirical evidence to support Dowling and Uncles' contention.

In response to this emerging understanding of the role of customer relationship management, researchers have started studying customer retention (e.g., Thomas, 2001; Mittal and Kamakura, 2001; Bolton, 1998; Smith, Bolton, and Wagner, 1999). To date, this research has focused almost exclusively on collecting customer satisfaction data (mainly in service industries) to understand customer defection and the revenue streams arising from active customers. This emerging literature has uncovered some key levers that may be used to influence the lifetime value of customers, such as raising customer satisfaction and thereby lowering defection rates, or raising individual-level purchases.

The second component of customer lifetime value, the value of each customer-firm interaction, has also been the subject of academic inquiry. Bult and Wansbeek (1995) propose to optimally select the target customer list for a mailing to maximize the profitability of each send. This is achieved by equating the marginal cost of sending the catalogs to the marginal expected revenue from the list. Bitran and Mondschein (1996) study list selection decisions in an environment where budget constraints force the company to divide resources between sending costs and inventory costs. Further, Gönül and Shi (1998) make consumer response endogenous by linking the purchase decision to past actions. When maximizing expected revenues, these papers do not explicitly study the duration of the relationship. They assume away retention; they also take the frequency of mailing as exogenous to the problem.

In this paper, we bring together these two research steams (duration and value maximization) by studying the timing decision (i.e., how often should a firm contact its customers) and its impact on both retention and consumer response. This study examines the 
tradeoff between short-term profitability and customer retention. In so doing, this study extends what we know about customer lifetime value (e.g., Bult and Wansbeek, 1995; Berger and Nasr, 1998), and customer relationship management (e.g. Sheth and Parvatiyar, 1995; Morgan and Hunt, 1994).

The next section presents the Customer Equity model underlying our empirical investigation. We then describe the data and present our empirical analysis. These results are followed by an optimization exercise that demonstrates the importance of selecting the right communication periodicity. The final sections discuss our findings and managerial implications.

\section{Database Value Model}

Setting the optimal email periodicity is a far reaching decision that must be evaluated with a long term perspective. We take the perspective of a marketing manager responsible for deriving the maximum long run profits out of a database of email addresses. The manager sends email to his database on a regular basis (every $\tau$ periods). Respondents who open the email can click on one of its links to purchase the good(s) promoted. New names are added to the database through acquisition, names exit the database through attrition. We will assume here that the acquisition process is not under the control of the manager and that his sole duty is to monetize the list of names, knowing that he can count on a regular influx of new names

From the firm's standpoint, the value of building and maintaining the database (i.e., its Customer Equity) can be written as (Drèze and Bonfrer 2005):

$$
C E(\tau)=(R(\tau) \bar{S}(\tau)-F C) \frac{(1+r)^{\tau}}{(1+r)^{\tau}-1}-A Q(g) \frac{(1+r)}{(1+r)-1} .
$$

where:

$r \quad$ is the per period discount rate 
$\tau \quad$ is the periodicity of contact (i.e., number of periods elapsed between emails, and normalized to equal one if this periodicity is annual),

$R(\tau)$ is the expected profit per customer for each email,

$\bar{S}(\tau)$ is the number of people in the database,

FC is the fixed cost associated with each email (e.g. creative and campaign setup costs),

$A Q(g)$ is the cost incurred to acquire $g$ new names every period.

If we take the acquisition process as given and producing an average of g names per period, we look at the problem of the marketing manager as maximizing the return from the database, or:

$$
V_{d b}(\tau)=(R(\tau) \bar{S}(\tau)-F C) \frac{(1+r)^{\tau}}{(1+r)^{\tau}-1} .
$$

For any given stream of new names $(g)$, the long tem size of the database is given by:

$$
\bar{S}(\tau)=\frac{\tau \cdot g}{1-P(\tau)},
$$

where $P(\tau)$ is the per email retention rate. For instance, if a firm acquires 100,000 names per year $(g=100,000)$ and sends monthly email $(\tau=1 / 12)$ that produce a retention rate of $95 \%$ then $\bar{S}(1 / 12)=166,666$.

The revenue derived by the firm from each email $(R(\tau))$ depends on the response of each customer to the email. We model the customers' response to each email using a two-stage process. In the first stage, the email is delivered to the mailbox, and the recipient can choose to open the message or not. In the second stage, and conditional upon opening, the recipient can proceed to a purchase page by clicking on a link in the email. Benefits for the firm arise in two ways. If the email recipient clicks on the email link (and purchases), the firm derives immediate 
revenues from the sale of the product promoted in the email. If the recipient opens the email but fails to click, there may still be some "billboard benefits" resulting from the recipient’s exposure to the message (e.g., a sale might still occur later or through another channel).

To set up our equation for the expected return, we denote $p_{o}$ and $p_{c}$ as the probability of open and click, respectively. We assume a billboard benefit to the firm of $\sigma$ if the recipient opens the email but does not click on any links, and an (expected) sales benefit of $x$ if the recipient actually clicks on the email. We then write the expected return from an email as (assuming variable costs of sending the email of $V C$ ):

$$
R(\tau)=p_{o}(\tau) *\left(\sigma+p_{c}(\tau) * x\right)-V C .
$$

Note that $p_{\mathrm{o}}$ and $p_{\mathrm{c}}$ are both dependent on $\tau$. The value $\sigma$ represents the expected value of a customer who opens the email but does not respond to it. The value $x$ represents the additional value of a customer who clicks on the email. It is important to note that for different firms, the relative magnitude of these two customer value metrics is likely to vary. This is due to the likely varying content of the promotional messages. It also depends on the objective of the firm. For a sales promotion, the objective of the firm is some direct call to action, in which case it is expected that $x>>\sigma$. On the other hand, if the objective of the email communication is to raise awareness then this is likely to result in $x<\sigma$. For example, a campaign designed to generate awareness of a launch of a product but otherwise requires no direct response, is likely to have $x=0$.

\section{Empirical Analysis}

In the previous section, we developed a general expression for the value of a database name. It has three basic parts, the overall database value equation (1), the database size equation 
(2), and an equation for the revenue per email for each customer (3). The database value is dependent on the periodicity of contact ( $\tau)$ through its impact on customer retention $(P(\tau))$, the likelihood of opening an email $\left(p_{o}(\tau)\right)$, and the likelihood of clicking on the email links $\left(p_{c}(\tau)\right)$. Equipped with this model, we can estimate its components using a database of a variety of email campaigns, and we can then study how the time between emails affects customer retention and customer equity.

\subsection{Description of the Data}

The data used in the empirical application were provided by a large entertainment products company. The company is building its on-line distribution presence and expanding its communications efforts via electronic channels. A significant proportion of its on-line communication activities takes the form of email updates on newly released video titles, as well as promotions for existing titles. Data was collected for 31 separate email campaigns for a variety of different promotions. The overall open and click rates and several ancillary statistics are reported in Table 2; a histogram of the inter-email time ( $\tau$, in weeks) observed in the data is shown in Figure 1.

Our dataset covers about two and a half million emails. These emails included tracking codes to enable us to observe whether the recipient opened the email and, if the email was opened, if the user clicked on any link contained in the email. We could also track whether the recipients unsubscribed from the newsletter following the receipt of one of the emails.

\subsection{Base parameters $r, V C, g, F C$}

Of all the parameters in (1) the discount rate of money $(r)$, the variable cost of sending one email $(V C)$, the cost of developing and sending an email campaign $(V C)$, the acquisition rate of new 
email addresses (g), are defined exogenously and can be obtained from the company's accounting (or project management) records. The company that provided us with the data routinely uses a discount rate of $10 \%$ for its financial projections. We will thus use the same value for $r$. The company out sources the sending of the emails and incurs a VC of $\$ 0.01$ per email sent.

As the company is protective about its database and its expansion efforts, we are not able to disclose the actual acquisition figures in this paper. Thus, for our illustration, we will use a somewhat arbitrary figure of 10,000 per week for $g$ and $\$ 5,000$ for $F C$.

\subsection{Email Message Value: $R(\tau)$}

Of the 2,548,362 emails that were sent, 354,449 were opened (i.e., Open Rate $=13.9 \%$ ). Further, 51,262 of the emails generated a click-through (i.e., Click-Through Rate $=14.5 \%$ ). This clickthrough rate based on the total number of emails sent (around 2.01\%) is in line with the North American average for the first quarter of 2005 (2.4\%, DoubleClick 2005).

The company executives attach a relatively small value to the billboard effect $(\sigma)$ derived from an open without a click. Although they recognize that there will be value through heightened awareness, and that users might decide to buy the product at another online retailer (e.g., Amazon) or at an offline store (e.g., Blockbuster) they set $\sigma$ at $\$ 0.01^{1}$.

Estimating $x$ was made possible by looking at the profits generated by the various email campaigns. One should note that we are looking here at the purchases that are directly attributable to specific campaigns. That is, we only take into account purchases made at the

\footnotetext{
${ }^{1}$ We have discussed the possibility to perform a post-email survey using a control group to measure the increase in purchase probability due to receive an email. Unfortunately, the company did not see this as a priority.
} 
company's online store when the user clicks, not at any purchases made on subsequent visits or at different retailers. From historical data, $x$ is estimated at $\$ 2.30$.

To complete our estimate for $R(\tau)$ we need estimates for the open and click probabilities. As discussed earlier, these probabilities are likely to be dependent on $\tau$. To model the relationship between inter-email time and both open and click probabilities, two binary logit regressions are fitted to the data. As we assume that the users do not know the content of the message before they open it, we model the click probability as conditional on open and thus estimate two separate logit models rather than one nested logit (statistical tests failed to support the need for a nested logit). We use a standard binary logit model for both the open rate and the conditional click rate.

\subsection{Retention Probability: $P(\tau)$}

58,198 of the 2,548,362 emails generated unsubscribe requests (i.e., overall retention rate $=$ 97.7\%). Just as we use a logit specification to model open and click rate, and consistent with the premise that users remain subscribed to the newsletter as long as the expected utility is larger than some threshold, we use a logit specification to model retention rate. For the retention probability, as opposed to the open and click probabilities, we include not only the time since the last email as a covariate, but also the square of the time since last email. We do this to allow for the fact that as discussed earlier, the retention probabilities are most likely inverted-U shaped with too few contacts just as detrimental as too many.

\section{Empirical Results}

We ran the three logit regressions described in the preceding section on four different subsets of the database. We first ran the regression on the whole database. Next, to see how differently the 
firm would behave if it segmented its database (Zeithaml, Rust, and Lemon 2001, Berger et al 2002), we ran separate regressions for each of the three gender codes contained in the database: Male (12.6\% of the database), Female (9.4\%), and Unknown (78.0\%).

\subsection{Estimation of Retention, Open and Click Probabilities}

Table 2 presents the estimation results for all three binary logit models. All variables are significant at the $p<.0001$ level in all three models. For the retention probability, the parameter values for $\tau$ (time since last email) are positive while the parameters for $\tau^{2}$ are negative in all four regressions. This yields an inverted-U shaped response function of retention probability to email frequency.

To help interpret the coefficients of the logit regression, we plot the Retention, Open, and Click probabilities as a function of $\tau$ in figures 2a to 2c. It can be seen that the Retention rate is inverted-U shaped, rising (as the inter-email time increases) up to a maximum then decreasing. The location of the maximum varies greatly depending on the target audience; if one does not differentiate among recipients, the optimal inter-email time from a retention standpoint is 113 days. This is almost identical to the optimal inter-email time for males (112 days), but much larger than for females (90 days).

Caution must be taken when interpreting the estimated coefficients across genders. One would expect that since all recipients are either male or female (we think that the belief that there are many dogs browsing the Internet is an urban legend), we should see the curve for the unknown gender lie in between the curve for male and female. Our results, however, suggest that this is not the case. These results may appear counter-intuitive, but they can be explained as follows: the users who provide gender information take an extra step that other users do not take. 
This is an extra 'cost' to the user and will only be incurred if the users believe that the newsletter is worth making an extra (albeit small) effort. In other words, customers self-select themselves not only based on providing gender information, but also based on how much effort they are willing to expend to be part of this newsletter. It is thus not surprising that these users are also less likely to defect.

In terms of open probabilities, we see a decreasing likelihood of opening the email as more time elapses between emails for both males and females; this decline is much more pronounced for female. Open probabilities increase in $\tau$ for those recipients who have declined to reveal their gender, and given the large weight given to this group, they also increase for the database as a whole. The difference in behavior between this group and the known groups is likely due to the same reason as the difference in retention behavior. The known groups have indicated a stronger interest in the newsletter and thus one can expect that they would respond well to more frequent emails.

The click probabilities given that the customer has opened an email show a decreasing pattern for all groups. The unknown gender group has click likelihoods roughly half of those of the other two groups. Overall we find that men are both more likely to open an email communication and click on it than women. The combination of the higher open rate and the higher click-through rate works in tandem, making men significantly more likely than women to respond to the email. Men are also more likely than women to stay in the database given that they were sent an email. This combination of factors makes men a much more attractive demographic for our sponsoring firm.

These results clearly show the importance of communication timing on consumer response. They also show that one cannot have a myopic approach to optimizing the 
communication periodicity. Indeed, optimal retention calls for waiting 3 to 4 months between newsletters while conditional click rates call for frequent emails. The firm must then trade off customer retention (long inter-email times) for customer activity (short inter-email time). It must do so in the context of the long-term database value it creates through its marketing actions; or, in other words, through its Customer Equity.

\subsection{Customer Equity and the Benefits of Targeting}

For the firm to properly optimize its inter-communication interval, it must plug the estimates derived in the previous section into the Customer Equity equation developed in section 3. The critical parts of the $C E$ formulation are the long-term database size and the expected revenues per customer per email. We plot those along with the inferred $C E$ in figures 3a-3c. In these plots, we assumed that the proportion of each gender is the same in the current database as it is in newly acquired group of names. ${ }^{2}$

Figures $3 \mathrm{a}$ and $3 \mathrm{~b}$ illustrate the tension that exists between growing the database and harvesting it. The database reaches its maximum size for large inter-email times (141 days for males and 115 days for females). This is natural since subscribers generally are only prompted to unsubscribe after receiving an email. If they do not receive any emails they are unlikely to unsubscribe. However, if they never receive an email, they are also unlikely to purchase from the firm.

The net result of the trade off between immediate revenues and database size is an interemail time of 85 days if one does not segment. If one were to create separate newsletters for each

\footnotetext{
${ }^{2}$ As discussed in Drèze and Bonfrer (2005), this is not strictly correct as the current database represents a cleanedup version of the acquisition stream. The unknown group having a higher tendency to defect than males or females, it is under-represented in the database as compared to the acquisition stream. Nevertheless, as these examples are used for illustrative purpose only, the difference between the two is inconsequential.
} 
of the genders (and bear the cost of three different newsletters), one would contact females every 73 days, males every 96 days, and the rest of the database every 163 days. One should note that the $C E$ response function is asymmetrical. Short inter-email times lead to negative customer equity. The losses are due to rising costs of creating new content $(F C=\$ 5,000$ per email) and the rising attrition.

\section{Managerial discussion and Conclusion}

The analysis developed in this paper is a practical application of the concept of customer equity. We study how inter-communication time, a largely ignored dimension, impacts $C E$. In doing so we are among the first to make the mailing decision endogenous. Our analysis demonstrates that it is important to take a holistic approach when optimizing marketing actions. More specifically, we find that:

- Inter-communication time $(\tau)$ has a dramatic impact on customer behavior. It affects both attrition and customer purchases and thus has a critical impact on customer equity.

- The impact of inter-communication time on lifetime value is highly asymmetrical. Managers are advised to err on the side of longer rather than shorter intercommunication times.

- The desire for high retention rates $(P)$ and high per-communication revenues $(R)$ work as opposing forces when computing the optimal inter-communication time. Retention rate begs for long inter-communication times, revenues beg for short inter-communication times.

We have taken a long-term approach in our model development. The firm is assumed to maximize the net present value of all its future actions. This is probably a reasonable assumption 
for large established firms or for firms that have a diversified portfolio of products. For startup firms, this might be a luxury they cannot afford. Indeed, in order to enjoy the benefits of future actions, one must still be in business in the future. Thus, firms may face a constrained optimization, and maximize $C E$ subject to generating sufficient short-term sales to recover operating expenses.

What if one does not observe attrition? Catalogs, for instance, often only see partial attrition. That is, they may be notified that a person has moved. But they rarely observe the attrition from people who are not in the market anymore. In the absence of a process where customer clearly state that they do not wish to receive further contacts from the firm, one can use the framework developed by Schmittlein, Morrison, and Colombo (1987) and validated by Schmittlein and Peterson (1994). Indeed, Schmittlein et al (1987) propose a methodology to estimate the probability that a customer is still alive, at a given point in time, given their past (in)activity.

As with most research, several limitations are present in our study. First, we only model whether or not an email was opened and/or clicked on. We do not attempt to model how many times an individual email was opened, or how many times a user clicked on an email link. We assume that the magnitudes of $\sigma$ and $x$ are the same if a user opened the same email 10 times or only once. That is, we are interested in the number of emails that were opened at least once, rather than the number of emails required to generate the effect $\sigma$, since we do not have any further information about the individual effectiveness of multiple opens. A challenge for subsequent research is to study the impact of multiple opens of a single email (e.g., via the mere exposure effect) and how these multiple opens may impact the value of an open ( $\sigma$ ) differently. 
Second, subscribers to the newsletter were not told about the inter-communication time ( $\tau$ ) prior to subscribing. On the one hand, this makes it difficult to support the assumption that recipients know this $\tau$ and can react accordingly. On the other hand, this gives us the opportunity to generate empirical estimates on the effects of $\tau$ on the likelihood of open, unsubscribe, and click-through (a natural field experiment) since we are able to observe (in a panel-like environment) the effects of varying the frequency.

Further limitations of this study are the lack of carryover effects of multiple communications over time as well as the limited modeling of customer heterogeneity. These are two important problems to study. However, we did not want to confuse the theoretical issues with practical implementation problems. We do intend to further investigate these problems, giving them the full attention they deserve. 


\section{References}

Bendapudi, Neeli and Leonard L Berry (1997), “Customers’ Motivations for Maintaining Relationships with Service Providers,” Journal of Retailing, 73 (1), 15-37.

Berger, Paul D., Ruth N. Bolton, Douglas Bowmanm, Elten Briggs, V. Kumar, A. Parasuraman, and Creed Terry (2002), “Marketing Actions and the Value of Customer Assets: A Framework for Customer Asset Management,” Journal of Service Research, 5 (1), 39-54.

Berger, Paul D. and Nada I. Nasr (1998), “Customer Life Time Value: Marketing Models and Applications,” Journal of Interactive Marketing, 12 (1), 17-30.

Bitran, Gabriel R. and Susana V. Mondschein (1996), "Mailing Decisions in the Catalog Sales Industry,” Management Science, 42 (9), 1364-1381.

Blattberg, Robert C. and John Deighton (1996), “Manage Marketing by the Customer Equity Test,” Harvard Business Review, July-August, 136-144.

Bolton, Ruth (1998) “A Dynamic Model of the Duration of the Customer’s Relationship with a Continuous Service Provider: The Role of Satisfaction,” Marketing Science, 17,1 45-65.

Bult, Jan Roelf and Tom Wansbeek (1995), “Optimal Selection for Direct Mail,” Marketing Science, 14 (4), 378-394.

DoubleClick (2005), “DoubleClick Q1 205 EMEA Email trend report shows all-time high delivery rates,” http://emea.doubleclick.com/UK/press/default.asp?p=92.

Dowling, Grahame R. and Mark Uncles (1997), “Do Customer Loyalty Programs Really Work?,” Sloan Management Review, Summer, 71-82.

Drèze, Xavier and André Bonfrer (2005), “Moving from Customer Lifetime Value to Customer Equity,” working paper. 
Gönül, Füsun and Meng Ze Shi (1998), “Optimal Mailing of Catalogs: A New Methodology Using Estimable Structural Dynamic Programming Models,” Management Science, 44 (9), 1249-1262.

Gönül, Füsun and Frenkel Ter Hofstede (2003) “A New Empirical Approach to Catalog Mailing Decisions," Working paper, McCombs School of Business, University of Texas at Austin.

Mittal, Vikas, and Wagner A. Kamakura (2001), “Satisfaction, Repurchase Intent, and Repurchase Behavior: Investigating the Moderating Effect of Customer Characteristics,” Journal of Marketing Research, XXXVIII (February), 131-42.

Morgan, Robert M and Shelby D. Hunt (1994), "The Commitment-Trust Theory of Relationship Marketing,” Journal of Marketing, 58 (July), 20-38.

Reichfeld, Frederick F. and Thomas Teal (1996), The Loyalty Effect. Boston: Harvard Business School Press.

Reinartz, Werner J. and V. Kumar (2000), “On the Profitability of Long-Life Customers in a Noncontractual Setting: An Empricial Investigation and Implications for Marketing,” Journal of Marketing, 64 (October), 17-35.

Rust, Roland T., Katherine N. Lemon, and Valarie A. Zeithaml (2004), "Return on Marketing: Using Customer Equity to Focus Marketing Strategy,” Journal of Marketing, 68 (January), 109-27.

Schmittlein, David C., Donald G. Morrison and Richard Colombo (1987), “Counting Your Customers: Who Are They and What Will They Do Next?,” Management Science, 33 (1), $1-24$. 
Schmittlein, David C. and Robert A. Peterson (1994), “Customer Be Analysis: An Industrial Purchase Process Application,” Marketing Science, 13 (1), 41-67.

Sheth, Jadish N. and Atul Parvatiyar (1995), "Relationship in Consumer Markets: Antecedents and Consequences,” Journal of the Academy of Marketing Science, 23 (4), 255-71.

Smith, Amy K., Ruth N. Bolton, and Janet Wagner (1999), “A Model of Customer Satisfaction with Service Encounters Involving Failure and Recovery,” Journal of Marketing Research, XXXVI (August), 356-372.

Thomas, Jacqueline S. (2001), “A Methodology for Linking Customer Acquisition to Customer Retention,” Journal of Marketing Research, 38 (May), 262-268.

Zeithaml, Valarie A., Roland T. Rust, and Katherine N. Lemon (2001), “The Customer Pyramid: Creating and Serving Profitable Customers,” California Management Review, 43 (4), 118-42. 


\section{Table 1: Data Description}

Number of email campaigns

Number of emails sent

$2,548,362$

Average number of emails per user

Number of opened emails

354,449

Number of clicks

51,262

Number of unsubscribe requests

58,198 
Table 2: Logit estimation results for probability of Retention, Open, and Click|Open .

\begin{tabular}{|c|c|c|c|c|c|}
\hline & & \multirow{2}{*}{ Overall } & \multicolumn{3}{|c|}{ Gender } \\
\hline & & & Unknown & Male & Female \\
\hline \multirow{5}{*}{ 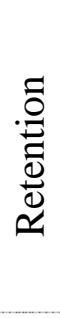 } & Intercept & $3.40^{*}$ & $3.12^{*}$ & $4.07^{*}$ & $4.01^{*}$ \\
\hline & Time since last email & $4.37^{*}$ & $1.99^{*}$ & $10.07^{*}$ & $11.08^{*}$ \\
\hline & Time since last email ${ }^{2}$ & $-7.09^{*}$ & $-1.39^{*}$ & $-16.41^{*}$ & $-22.45^{*}$ \\
\hline & $\mathrm{N}$ & $2,548,362$ & $1,512,718$ & 558,996 & 476,648 \\
\hline & $\chi^{2}$ & $2,786.90$ & $2,141.23$ & 775.42 & 1759.87 \\
\hline \multirow{4}{*}{ ठี } & Intercept & $-1.89^{*}$ & $-1.79^{*}$ & $-1.79^{*}$ & $-2.04^{*}$ \\
\hline & Time since last email & $0.39^{*}$ & $0.40^{*}$ & $-0.19^{*}$ & $-1.93^{*}$ \\
\hline & $\mathrm{N}$ & $2,548,362$ & $1,512,718$ & 558,996 & 476,648 \\
\hline & $\chi^{2}$ & $1,044.31$ & 898.98 & 31.12 & $1,247.87$ \\
\hline \multirow{4}{*}{ 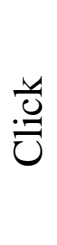 } & Intercept & $-1.51^{*}$ & $-1.94^{*}$ & $-0.90^{*}$ & $-1.35^{*}$ \\
\hline & Time since last email & $-1.69^{*}$ & $-1.26^{*}$ & $-1.74^{*}$ & $-0.72^{*}$ \\
\hline & $\mathrm{N}$ & 354,449 & 232,020 & 77,838 & 44,591 \\
\hline & $\chi^{2}$ & $2,752.46$ & 907.17 & 615.40 & 38.86 \\
\hline
\end{tabular}

${ }^{*}$ Significant at the $\mathrm{p}<.0001$ level. 
Figure 1: Empirical Inter-Email Times

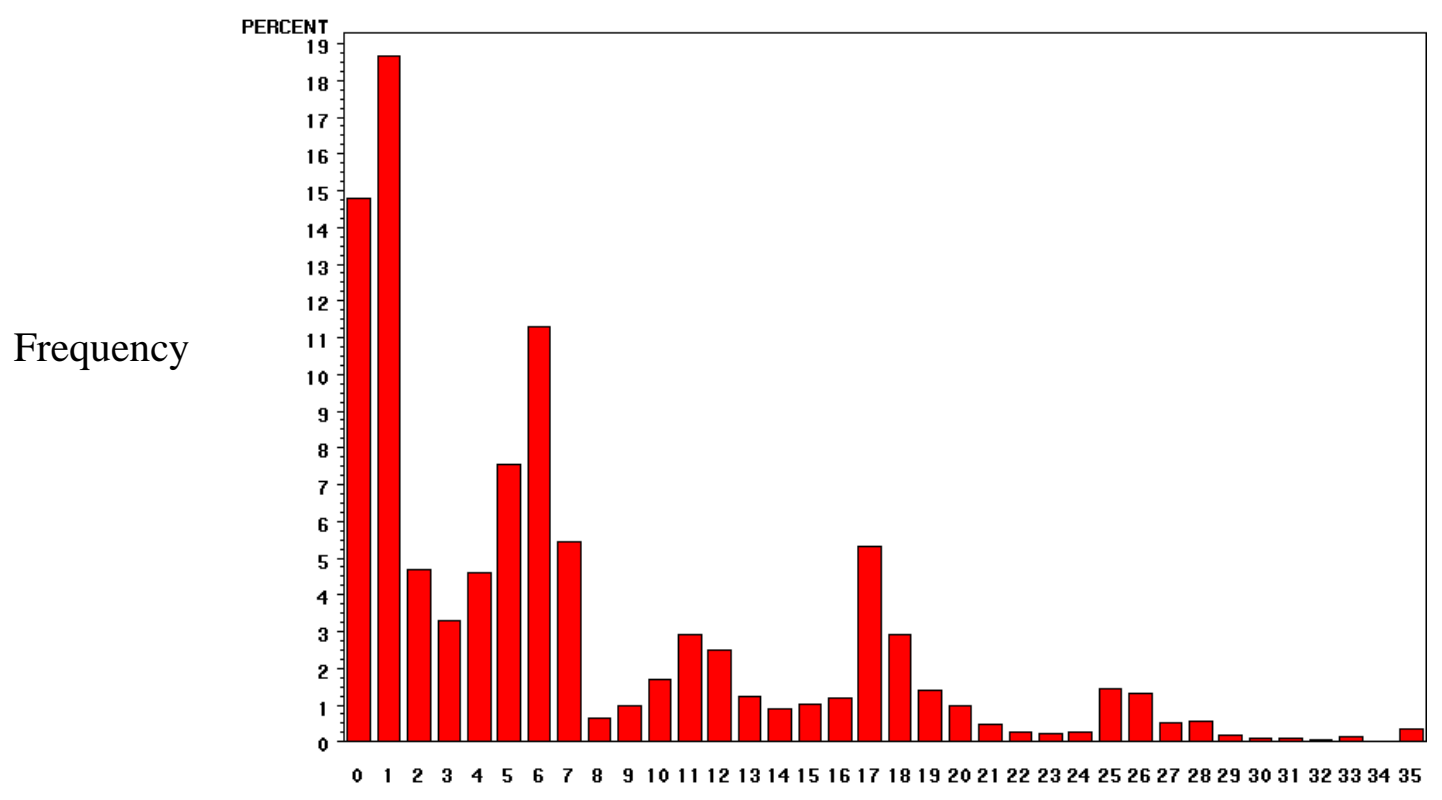

Number of Weeks since last email sent 
Figure 2a: Retention Probabilities

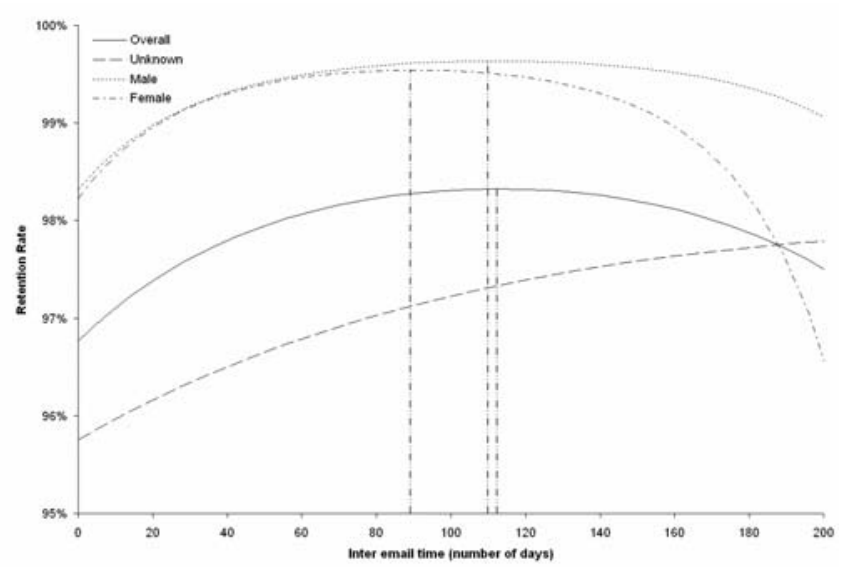

Figure 2b: Open Probabilities

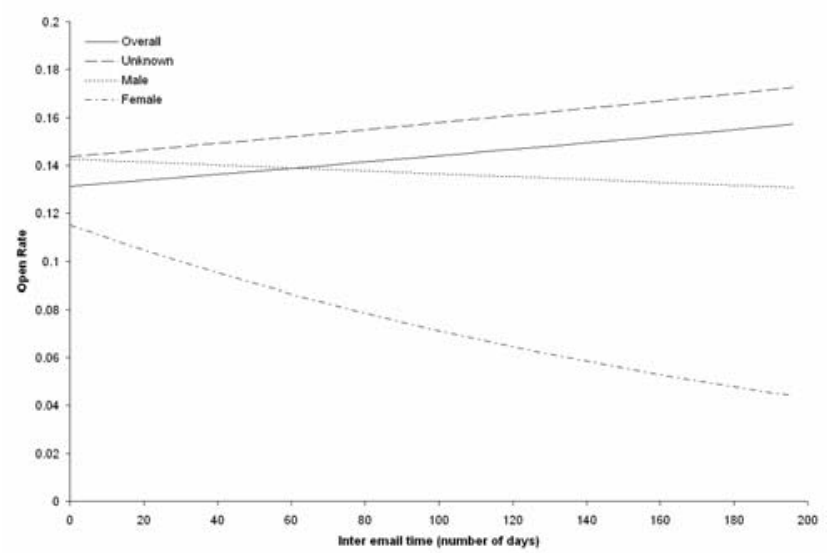

Figure 2c: Click Probabilities

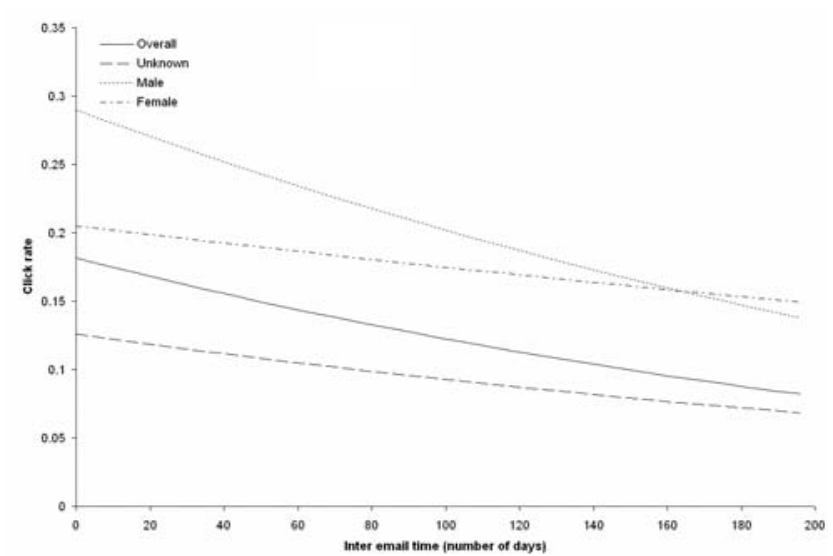


Figure 3a: Database Size

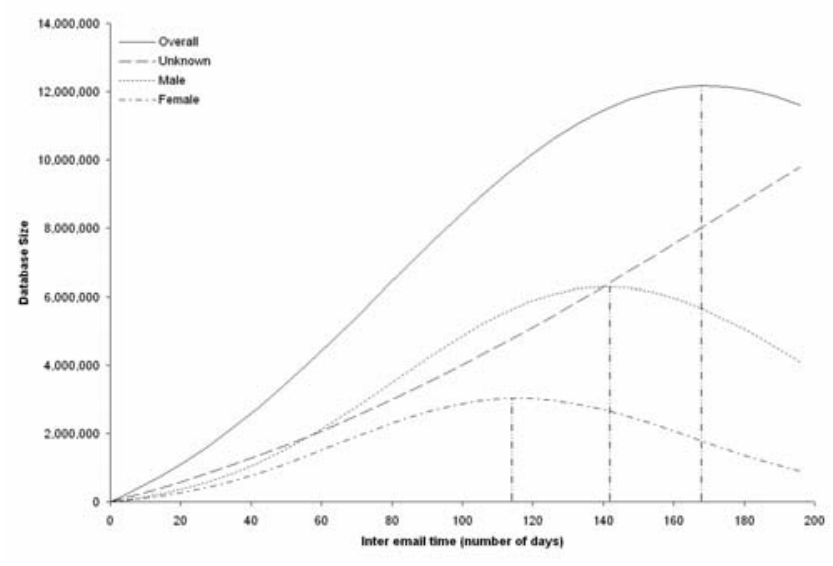

Figure 3b: Expected revenue per customer per email

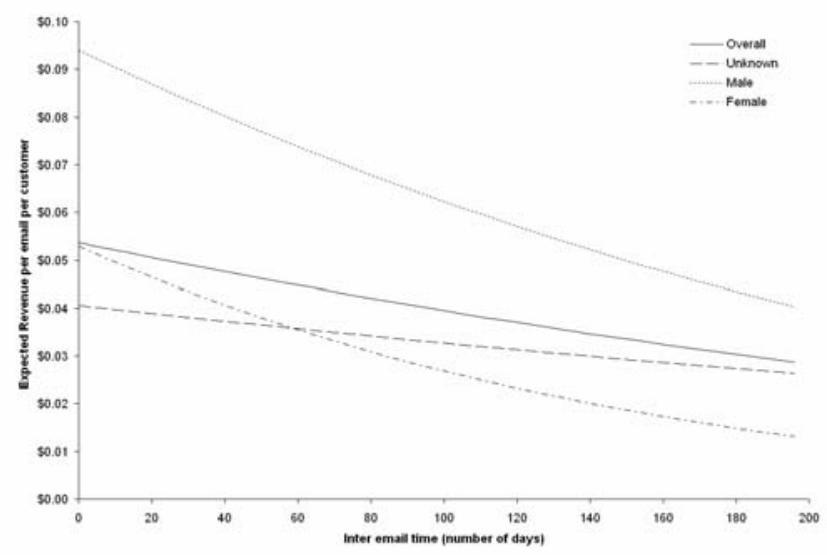

Figure 3c: Customer Equity

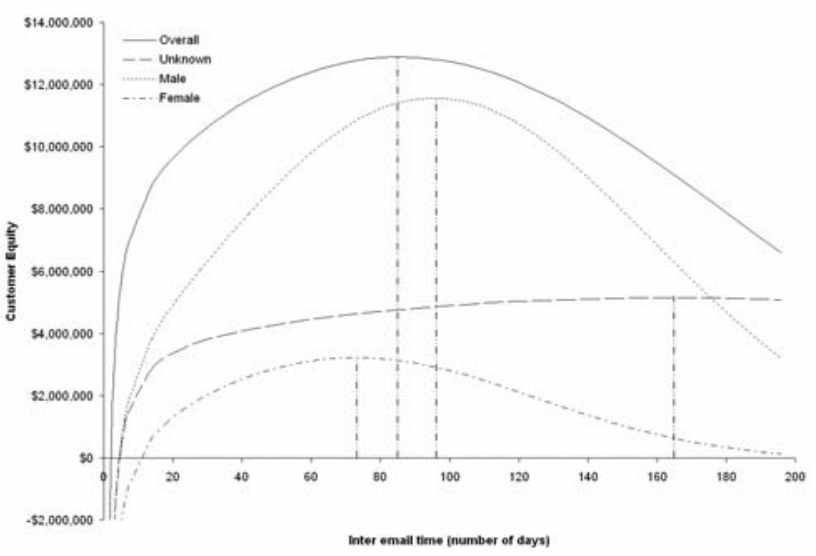

